\title{
What can MaxEnt reveal about high-density recordings and what can high-density recordings reveal about MaxEnt?
}

Dagmara Panas ${ }^{1 *}$, Alessandro Maccione ${ }^{2}$, Luca Berdondini², Matthias H Hennig ${ }^{1}$

From Twentieth Annual Computational Neuroscience Meeting: CNS*2011

Stockholm, Sweden. 23-28 July 2011

Recent advances in neural recording techniques open exciting possibilities of better understanding whole populations of neurons. Devices such as APS MEA (Active Pixel Sensor Microelectrode Array) [1,2] allow for simultaneous recordings from 4096 channels (64x64 grid) at near-cellular resolution (electrode size: $21 \mu \mathrm{m}$, electrode spacing: $42 \mu \mathrm{m}$ ) and constitute a potentially very rich and detailed source of information on the dynamics of neural systems. Such volumes of data are however difficult to analyse: simple measures such as
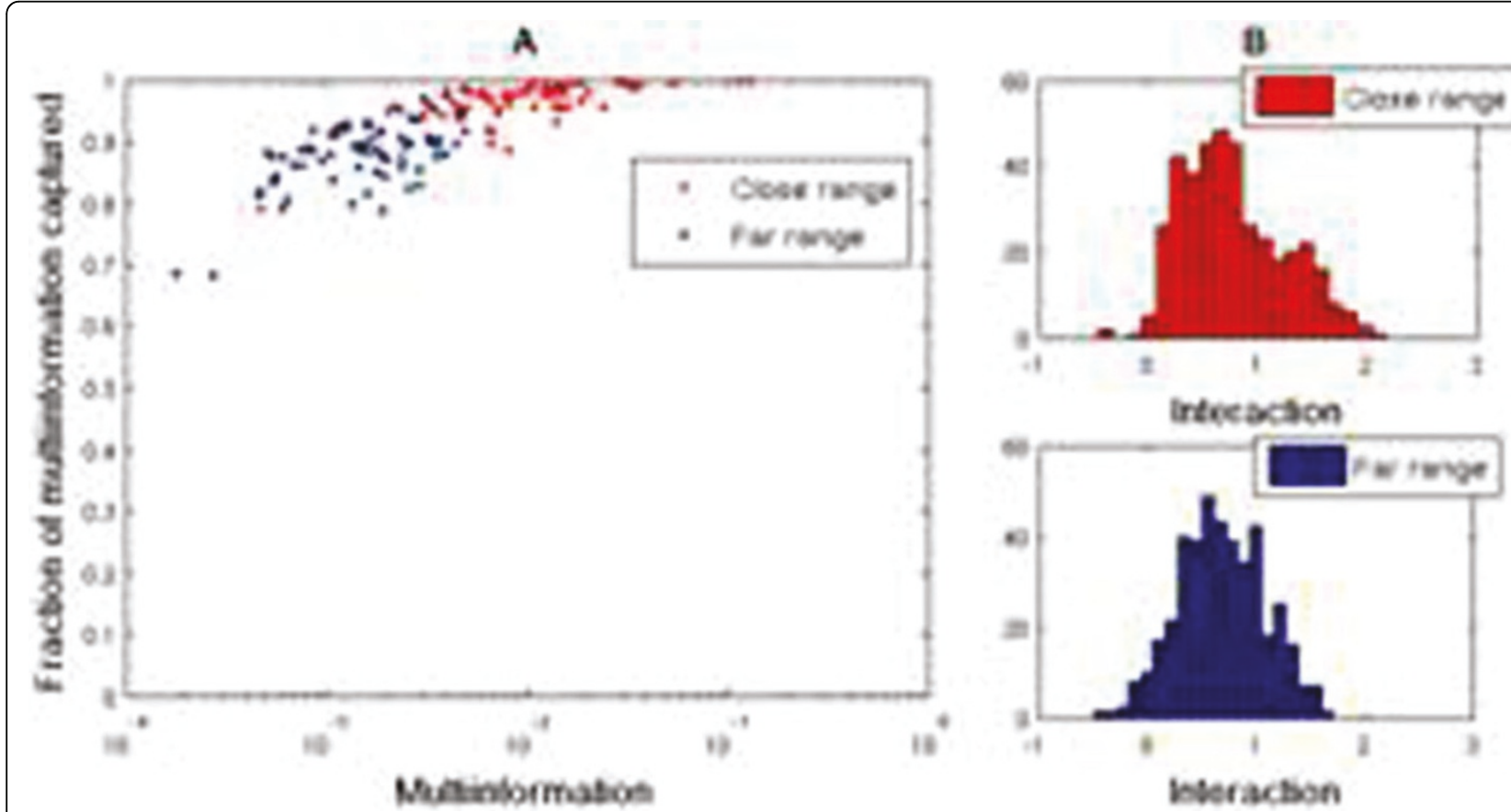

Figure 1 A Fraction of multiinformation captured by the MaxEnt model versus multiinformation (bits per bin, 5 ms bins used). B Histograms of the values of fitted interaction parameters.

\footnotetext{
* Correspondence: D.Panas@sms.ed.ac.uk

'Institute for Adaptive and Neural Computation, School of Informatics,

University of Edinburgh, EH8 9AB, UK

Full list of author information is available at the end of the article
} 
mean firing rates and correlations are often insufficient to capture interesting phenomena, while more sophisticated approaches can be computationally intensive and hard to interpret. Here we examine the applicability of pairwise maximum entropy (MaxEnt) [3-5] modelling to describe APS MEA data.

Pairwise maximum entropy model (equivalent to Ising model in physics), when fit to the data, yields a minimally structured probability distribution of network states that respects first and second order interactions. It is a convex, parsimonious and readily interpretable model that has been shown to characterize spiking patterns surprisingly robustly in many cases $[3,4]$. Additionally, it can provide a sensitive tool in detecting higherorder interactions. As reported in [5], the significant failure of the Ising model in close range $(<300 \mu \mathrm{m})$ uncovers a high-order processing mode in local clusters of neurons, a mode of processing absent on larger scale $(>600 \mu \mathrm{m})$ and undetectable with correlations.

In present work we examine the results and performance of the MaxEnt model fitting in different preparation types and parameter regimes; owing to high resolution recordings we can specifically focus on varying spatial scales. As can be seen in Fig.1, indeed even in cultured tissue data there are indicators of certain discrepancies between local populations and populations further apart. Firstly (panel A), it is in local populations where the advantage of Ising model over the independent model is most prominent. Secondly (panel B), the interactions within local populations reveal a different structure than those among groups of neurons spread further apart (Kolmogorov-Smirnov test, $\mathrm{p}<0.05$ ); and, importantly, this is not a feature that can be shown by correlation analysis.

\section{Acknowledgements}

This work was funded by EPSRC and BBSRC as part of Doctoral Training Centre programme at School of Informatics, University of Edinburgh(DP); MRC Fellowship G0900425 (MHH); and IDEA, FP6-NEST Grant 516432 (AM and $L B)$.

\section{Author details}

'Institute for Adaptive and Neural Computation, School of Informatics, University of Edinburgh, EH8 9AB, UK. ${ }^{2}$ Department of Neuroscience and Brain Technologies, Italian Institute of Technology, 16163 Genova, Italy.

Published: 18 July 2011

\section{References}

1. Imfeld K, Neukom S, Maccione A, Bornat Y, Martinoia S, Farine PA Koudelka-Hep M, Berdondini L: Large-scale, high-resolution data acquisition system for extracellular recording of electrophysiological activity. IEEE Trans Biomed Eng 2008, 55:2064-2073.

2. Berdondini L, Imfeld K, Maccione A, Tedesco M, Neukom S, KoudelkaHep M, Martinoia S: Active pixel sensor array for high spatio-temporal resolution electrophysiological recordings from single cell to large scale neuronal networks. Lab Chip 2009, 9:2644-2651.

3. Schneidman E, Bialek W: Ising models for networks of real neurons. Nature 2006, 440:1007-1012.
4. Tang A, Jackson D: A Maximum Entropy Model Applied to Spatial and Temporal Correlations from Cortical Networks In Vitro. J Neurosci 2008, 28(2):505-518.

5. Ohiorhenuan IE, Mechler F, Purpura KP, Schmid AM, Hu Q, Victor JD: Sparse coding and high-order correlations in fine-scale cortical networks. Nature 2010, 466:617-621.

doi:10.1186/1471-2202-12-S1-P146

Cite this article as: Panas et al:: What can MaxEnt reveal about highdensity recordings and what can high-density recordings reveal about MaxEnt? BMC Neuroscience 2011 12(Suppl 1):P146.

\section{Submit your next manuscript to BioMed Central and take full advantage of:}

- Convenient online submission

- Thorough peer review

- No space constraints or color figure charges

- Immediate publication on acceptance

- Inclusion in PubMed, CAS, Scopus and Google Scholar

- Research which is freely available for redistribution

Submit your manuscript at www.biomedcentral.com/submit
C Biomed Central 